\title{
Crossing boundaries: documentation of a teacher training course on design, robotics and coding ${ }^{1}$
}

\author{
Lorella Giannandrea ${ }^{\mathrm{a}}$, Francesca Gratani ${ }^{\mathrm{b}}$, Alessandra Renieri ${ }^{\mathrm{c}}$ \\ aniversity of Macerata, Italy, lorella.giannandrea@ unimc.it, https://orcid.org/0000-0002-1169-4795 \\ ${ }^{b}$ University of Macerata, Italy, f.gratani@ unimc.it, https://orcid.org/0000-0003-2974-0101 \\ ${ }^{c}$ University of Macerata, Italy, alessandra.renieri@unimc.it, http://orcid.org/0000-0002-4882-9083
}

\begin{abstract}
This article reports on the results of a teacher training course in which 41 teachers, working together with three university researchers, experienced a different way to engage in meaningful teaching and learning activities in design, coding and robotics. The course was run in an Italian school during the lock-down period of the Covid-19 pandemics. The training path had the objective to make the participants work differently, acting both as researchers and as teachers in training. The research reported in this article examined if and how an online teacher training course could act as a third space between school and academic cultures to achieve a negotiation of pedagogical practices.

Findings from the study, collected through pre-post questionnaires and open-ended discussions, highlight an improvement in knowledge related to coding and robotics. Moreover, during the course, teachers experienced a new approach to space-time dimensions, first-hand experimentation and a collaborative approach, leading to greater perceived confidence in their skills and competences.
\end{abstract}

Keywords: online teacher training, professional learning, teaching and learning, learning contexts

\section{Introduction}

The teachers' professional learning has recently received increasing attention in the research literature (Murray \& Male, 2005; Swennen, Shagrir, \& Cooper, 2009; van Velzen, van der Klink, Swennen, \& Yaffe, 2010). Timperlay et al. (2007) showed that one of the most relevant factors for improving the quality of learning in schools is represented by the preparation of individual teachers. Despite this, most of the training courses for teachers are focused on providing them with simple knowledge and skills, maintaining an approach in which teachers are not the protagonists, but the 'subjects' to whom an already defined path, arranged by others, is provided. In contrast, affording teacher autonomy and agency around professional learning is perceived as a value and a scope (Tardif, 2013; Wittorski, 2008). According to King (2019, p. 171), there is evidence that the impact of professional learning leads to more significant outcomes for teachers and students, but at various levels of the system, some teachers feel that they lack the necessary knowledge and skills to do so.

This knowledge gap could be addressed by creating a collaborative space between school teachers and university researchers, where teachers and researchers should work together (Flessner, 2014). The paper tries to answer the following questions: Can an online teacher training course act as a third space between school and academic culture? Which methodological elements enabled teachers to learn and achieve the aims of the course?

Potter \& McDougall (2017) state that third space is defined by practices of learning by doing, where teacher and researchers collaborate to achieve learning outcomes, sharing methods and thoughts. This collaborative work could enhance the teachers' perception of self-efficacy, developing a reflective attitude and a collaborative approach to the design tasks.

\footnotetext{
1 The article is the result of a common vision among the authors with the following responsibilities: Lorella Giannandrea is the author of Introduction and paragraph 1, Francesca Gratani is the author of paragraph 2 and Alessandra Renieri is the author of paragraphs 3 and 4.
} 


\section{Crossing boundaries: documentation of a teacher training course on design, robotics and coding Giannandrea, Gratani, Renieri}

The paper reports on a teacher training course organized in an Italian school during the lock-down due to Covid-19 pandemics. The characteristics of that path were precisely those of being halfway between a group of people who wanted to learn on their own, through mutual help, and a structured learning path proposed by the school administrator. It is a sort of zone between formal (the teacher training course organized by the school) and informal learning, where teachers designed together and gave and received advice from colleagues (even from different school levels) and researchers.

Understanding the nature of working in this third space, between formal learning and informal practices, is important in addressing the changing needs of the teachers, asking for different learning paths to cope with new literacy and new topics related to the 21 st-century skills.

\section{Third space}

The concept of a third space derives from the work by Bhabha (1994) and the further reflections by other researchers, for example, Engeström (2004) and Gutierrez (2008).

For Bhabha (1994), the term third space was developed to define communication, intended both as the production of meaning and as a complex act of 'cultural performance'. If we think about a communicative act between 'I' and 'You', we can recognize a 'pact of interpretation'. In this situation,

the production of meaning requires that these two places be mobilized in the passage through a third space, which represents both the general conditions of language and the specific implication of the utterance in a performative and institutional strategy of which it cannot 'in itself' be conscious. What this unconscious relation introduces is an ambivalence in the act of interpretation (Bhabha, 1994)

From the perspective of activity theory, Engeström (2004) suggested that there is a kind of horizontal movement between professional practice sites, and this movement is a crucial element in the learning that takes place in each site. Concerning teachers, it is possible to define a space for classroom practice and an environment made up of the theories and the concepts they studied in their initial or in-service training. There are spaces, of course, where these areas either overlap or interact. Engeström claimed that it was this 'theory of expansive learning that puts the horizontal and interorganizational dimension of learning in the center' (p. 15) and that working in these in-between spaces 'puts a heavy emphasis on bridging, boundary-crossing ... and negotiation ...' (p. 16). Further research by Engeström, Engeström and Kärkkäinen (1995) stated that this kind of learning could show some difficulties, especially when different practices conflict and create a sense of uncertainty. They found that people working in these hybrid spaces are exposed to different contexts and ways of enacting practice; as a result, they 'face the challenge of negotiating and combining ingredients from different contexts to achieve hybrid solutions ... [and] demands for dialogical problem-solving increase' (p. 319).

Zeichner (2010) argued that working within what he referred to as the hybrid space between schools and universities was an essential dimension of teacher education and training and that, in the field of teacher preparation, spatialized theorization has been mobilized to understand the intersections and interstices of the work of university and school: hybrid or third spaces are said to exist, for example, when practices cross the so-called academic and practitioner boundaries (Zeichner, 2010; Martin et al., 2011; Taylor et al., 2014; Williams, 2014).

According to Gutierrez et al. (1995), the key features of a third space are the peering logics, the experiential orientation, the motivation and the pleasure of 'doing together', and the absence of learning that was taught (Rivoltella, 2020). She said:

We proposed the idea of a Third Space where teacher and student scripts - the formal and informal, the official and unofficial spaces of the learning environment-intersect, creating the potential for authentic interaction and a shift in the social organization of learning and what counts as knowledge (Gutiérrez et al., 1995).

Moreover, Potter and McDougall (2017) highlight that if a training path is not strictly linked to the life and the experience of the learners, it is challenging to reach the intended outcomes, even if you are training teachers.

To sum up we are arguing here that school systems which do not work in some way with the lives of their learners in the context of their lived experience cannot, arguably, be said to be fully agentive in their approach, rather they are curriculum-centred and institution-facing. As a result, they cannot build on and develop skills and dispositions which are evident in the earliest social and cultural experiences of learners outside school, which is a prerequisite of the negotiation which enables a third space (Potter \& McDougall, 2017).

\section{Methods}

The course was held entirely online between May and June 2020 (7 weeks), using different platforms to support synchronous and asynchronous interactions. The reference platform for asynchronous interactions was Google Classroom, where materials, tasks and feedback were shared. Google Meet was used instead for all the synchronous meetings. 


\section{Crossing boundaries: documentation of a teacher training course on design, robotics and coding Giannandrea, Gratani, Renieri}

The course was mainly divided into two parts, and it followed the schedule reported in Table 1.

Table 1. The training course schedule.

\begin{tabular}{|c|c|c|}
\hline Kindergarten & Primary school & Lower secondary school \\
\hline \multicolumn{3}{|c|}{ Initial plenary meeting (1 hr) } \\
\hline $\begin{array}{l}\text { Video recorded lesson with assigned task } \\
\text { on Cody Roby } \\
\text { (20 min) }\end{array}$ & $\begin{array}{l}\text { Video recorded lesson with assigned task } \\
\text { on Hour of Code } \\
\text { (24 min) }\end{array}$ & $\begin{array}{l}\text { Video recorded lesson with assigned task } \\
\text { on Binary Numbers System } \\
\text { (20 min) }\end{array}$ \\
\hline $\begin{array}{c}\text { Video recorded lesson with assigned task } \\
\text { on Cody Feet } \\
\text { (19 min) }\end{array}$ & $\begin{array}{c}\text { Video recorded lesson with assigned task } \\
\text { on Scratch } 1 \\
\text { (36 min) }\end{array}$ & $\begin{array}{c}\text { Video recorded lesson with assigned task } \\
\text { on Algorithms } \\
(24 \mathrm{~min})\end{array}$ \\
\hline $\begin{array}{l}\text { Video recorded lesson with assigned task } \\
\text { on Bee Bot } \\
\text { (21 min) }\end{array}$ & $\begin{array}{c}\text { Video recorded lesson with assigned task } \\
\text { on Scratch } 2 \\
\text { (24 min) }\end{array}$ & $\begin{array}{c}\text { Video recorded lesson with assigned task } \\
\text { on Scratch } 3 \\
(24 \mathrm{~min})\end{array}$ \\
\hline Restitution meeting (1 hr) & Restitution meeting ( $1 \mathrm{hr}$ ) & Restitution meeting (1 hr) \\
\hline $\begin{array}{l}\text { Meeting on designing with assigned task } \\
\qquad(1 \mathrm{hr})\end{array}$ & $\begin{array}{l}\text { Meeting on designing with assigned task } \\
\qquad(1 \mathrm{hr})\end{array}$ & $\begin{array}{l}\text { Meeting on designing with assigned task } \\
\qquad(1 \mathrm{hr})\end{array}$ \\
\hline \multirow[t]{2}{*}{ Restitution meeting ( $1 \mathrm{hr}$ ) } & Restitution meeting ( $1 \mathrm{hr})$ & Restitution meeting (1 hr) \\
\hline & Final plenary meeting ( $1 \mathrm{hr})$ & \\
\hline
\end{tabular}

The next subsections provide a detailed description of the participants and the two phases of the course.

\subsection{Participants}

The course was attended by 41 teachers from the institute 'Egisto Paladini' of Treia, in the province of Macerata (Italy), ranging from kindergarten to lower secondary school.

Before the beginning of the course, participants were asked to fill in some forms to detect personal information (gender, educational qualification, background), information about their professional life (years of teaching, educational stage, types of teaching) and issues linked with the topics of the training course (e.g., if they had had previous training experiences related to coding and/or robotics, if they had carried out coding and/or robotics activities in class).

Depending on how many participants filled the forms in, we collected data concerning the personal information of a sample of 40 teachers (see Table 2) and the professional life of a sample of 37 teachers (see Table 3 ).

Table 2. Summary of data concerning personal information.

\begin{tabular}{lll}
\hline Features & Index & Value (\%) \\
\hline Gender & F & 95 \\
& M & 5 \\
Educational qualification & Diploma & 35 \\
& Degree & 57.5 \\
& Post-degree qualification & 5 \\
& PhD & 2.5 \\
Background & Humanities and social studies & 82.5 \\
& Scientific studies & 10 \\
& Juridical studies & 7.5 \\
\hline
\end{tabular}


Table 3. Summary of data concerning professional life.

\begin{tabular}{lll}
\hline Features & Index & Value (\%) \\
\hline In-service teaching years & $0-10$ & 40.5 \\
& $11-30$ & 48.7 \\
& $>30$ & 10.8 \\
Teaching educational stage & Kindergarten & 29.7 \\
& Primary school & 62.2 \\
& Lower secondary school & 8.1 \\
Teaching & Support teaching & 21.6 \\
& Curricular teaching & 78.4 \\
\hline
\end{tabular}

The majority of participants $(56.8 \%)$ stated that they had had previous training experiences in coding and/or robotics. Among them, most had attended training courses lasting more than 5 hours (42.9\%). In comparison, a minority participated in basic experiences lasting less than 5 hours $(28.6 \%)$ or carried out individual training (books, magazines, tutorials, etc.) $(23.8 \%)$. One participant finally reported that she had trained during a specialization workshop for support teaching. Moreover, $43.2 \%$ of all participants claimed that they had carried out classroom activities related to coding and/or robotics before this course. Almost all of them had performed unplugged coding activities.

\subsection{Course description}

\subsubsection{Introduction}

As shown in Table 1, the course developed along three main strands, corresponding to the three educational teaching stages. After a preliminary meeting to introduce the course to all participants (objective, structure, topics, etc.), lectures and activities for each educational stage were designed together with the teachers. However, it is important to underline that all materials were shared with all the participants and all the meetings were also open to all of them. Thus, regardless of the level s/he was teaching, every teacher was free to choose which materials to view, tasks to complete and meetings to attend. This type of participation to the course aimed at promoting an interdisciplinary and vertical curriculum, and a pull approach (Hagel, Brown, \& Davison, 2012).

As already mentioned, two main phases were foreseen: first technical and theoretical phase for the presentation of topics and devices and second design phase dedicated to the planning of collaborative activities on coding and/or robotics.

\subsubsection{Description Part 1}

The first part of this training course can be seen as a 'technical' introduction on different devices (as 'Cody Roby'2, 'Cody Feet', 'Bee bot'4, 'Scratch'5 and 'Hour of code' ${ }^{6}$ ) and on two main IT concepts ('binary numbers system' and 'algorithms').

For each subject, we recorded a short video (from 20 to 40 minutes long) containing an introduction to the devices/concepts and its potential use in the classroom in the last part of the video, and we asked the trainee to (optionally) perform some activities. Those were useful to become familiar and more skilled to become more conscious and aware during their future interaction in class.

Each participant had the opportunity to watch all of them as they wished. We suggested a simple division according to the organization in the school system: for kindergarten, we selected 'Cody Roby', 'Cody Feet' and 'Bee bot'. The first combines the idea of unplugged coding and the introduction of block-based visual programming language. We solved the lack of a physical device using the free 'Bee-Bot emulator platform'7 for the last one.

\footnotetext{
${ }^{2}$ http://www.codeweek.it/cody-roby/

3 http://codemooc.org/codyfeet/

${ }^{4} \mathrm{https://www.campustore.it/bee-bot-nuova-versione.html} \mathrm{(Italian} \mathrm{version)}$

5 https://scratch.mit.edu/

${ }^{6}$ https://hourofcode.com/it (Italian version) https://hourofcode.com/it/en

7 https://www.terrapinlogo.com/emu/beebot.html
} 


\section{Crossing boundaries: documentation of a teacher training course on design, robotics and coding Giannandrea, Gratani, Renieri}

For primary school, we created two videos to introduce the basic principles of 'Scratch' and another one for 'Hour of code'. For this last one, we described the project, and we reviewed several activities (like 'Lightbot', 'Blockly games', 'Compute-it', ...) we thought could be more meaningful.

For lower secondary school, we selected a high-level 'Scratch' video; we suggested the 'binary numbers system' and the 'algorithms' topics, with the idea of starting a comprehensive introduction towards IT.

\subsubsection{Description Part 2}

The second part of the course focused on planning from a collaborative and inclusive perspective. In the first three synchronous meetings, several collaboration strategies were introduced, according to the educational stage:

- Kindergarten: brainstorming, discussion and role-playing

- Primary school: jigsaw, debate and numbered heads

- Lower secondary school: peer review, case study and pyramid

At the end of each meeting, we assigned the task of designing either an activity or a path related to coding and/or robotics, considering inclusion of students and the cooperation among them. Designed learning paths, carried out individually or in groups, were then shown to the other teachers and the trainers at the subsequent restitution meetings. On these occasions, teachers received significant feedback from colleagues and trainers to review and improve their projects. Moreover, the negotiation between teachers and researchers led them to share their ideas and methodologies.

Another opportunity for mutual sharing and discussion took place at the final plenary meeting, where the conclusions of the course were drawn, and the last reflections exchanged.

Finally, we decided to create a shared repository in Google Classroom of all the materials and works that had been produced, which would remain available after the end of the course. In this way, the teachers who participated and those who could not will benefit from it for their work in the future.

\subsection{Assessment instructions}

The variables of interest were basic knowledge - both on the coding devices and the project design - and the different attitudes in approaching design tasks and new school activities.

We measured them in three different moments: 'before-course' (BC), 'post-course' (PC) questionnaires and during the synchronous/asynchronous activities (through the observations of personal dynamics, of the chat, of the emails, of the activities performed by the teachers and posted on classroom, ... ).

$\mathrm{BC}$ and $\mathrm{PC}$ tests were carried out through Google Forms.

The $\mathrm{BC}$ questionnaire was divided into three main topics:

- (A) Expectations on the training course (at a personal/professional level) - submitted by 38 participants

- (B) Proficiency on the theoretical knowledge of the devices presented in the training course - submitted by 40 participants

- (C) Description of the main and essential aspects used in the design of an educational path, such as 'inclusion', 'use of technologies', ...- submitted by 32 participants

The PC questionnaire was divided into other three main topics:

- (A) Satisfaction and recommendations on the course - submitted by 40 participants

- (B) Proficiency on the theoretical knowledge on the devices presented in the training course: we used the same BC-B test - submitted by 39 participants

- (C) (Meta)-consideration of the employment of the gained knowledge in the classes - submitted by 39 participants

The questions were not mandatory, so not all the participants had submitted the answers.

\section{Results}

\subsection{Knowledge pre-post questionnaires}

As we mentioned in Section 2.2.2, each participant had the opportunity to choose the 'technical' device described in a pull approach.

In Table 4, we can see the percentage of teachers who had chosen to view and carry out the proposed activities for each device/topic. 
Crossing boundaries: documentation of a teacher training course on design, robotics and coding

Giannandrea, Gratani, Renieri

Table 4. Percentage of viewing.

\begin{tabular}{ll}
\hline Presented devices & Value of teachers who viewed and carried out the proposed activities (\%) \\
\hline Cody Roby & 88 \\
Cody Feet & 80 \\
Bee Bot & 80 \\
Hour of code & 53 \\
Scratch & 67 \\
Binary numbers system & 24 \\
Algorithms & 17
\end{tabular}

In Table 5, we report the percentages of exact answers in the BC-B test and in the PC-B test. An improvement for each topic is evident, in particular for those who many participants chose. For topics selected only by a few teachers, the 'don't know' values remain high.

Table 5. Pre-post course awareness of the devices.

\begin{tabular}{llllll}
\hline Presented devices & $\begin{array}{l}\text { Value of exact } \\
\text { answers BC-B (\%) }\end{array}$ & $\begin{array}{l}\text { Value of 'don't } \\
\text { know' answers of } \\
\text { BC-B (\%) }\end{array}$ & $\begin{array}{l}\text { Value of exact } \\
\text { answers PC-B (\%) }\end{array}$ & $\begin{array}{l}\text { Value of 'don't } \\
\text { know' answers of } \\
\text { PC-B (\%) }\end{array}$ & $\begin{array}{l}\text { Increase of exact } \\
\text { answers from BC-B } \\
\text { to PC-B (\%) }\end{array}$ \\
\hline Cody Roby & 77.5 & - & 87.2 & - & $9.7 \%$ \\
Cody Feet & 62.5 & 15 & 92.3 & 2.5 & $29.8 \%$ \\
Bee Bot & 7.5 & 82.5 & 66.7 & 15.4 & $59.2 \%$ \\
Hour of code & 0 & 75 & 36 & 20.5 & $36 \%$ \\
Scratch & 7.5 & 50 & 36 & 15.4 & $28.5 \%$ \\
$\begin{array}{l}\text { Binary numbers } \\
\text { system }\end{array}$ & 20 & 55 & 25.7 & 51.3 & $5.7 \%$ \\
Algorithms & 5 & 92.5 & 28.2 & 61.5 & $23.2 \%$ \\
\hline
\end{tabular}

\subsection{New attitudes and habits}

Data from the PC-A and PC-C tests also revealed three great potentials of the course. First of all, when we asked teachers to name an added value of this distance course, $34.2 \%$ of them highlighted the opportunity to learn by doing, as well expressed by the answers below:

T1: 'Having to do it on my own has given me the input and the possibility to experiment by trial and error and activate a reasoned and conscious path'.

T2: 'They have increased my motivation to do it alone, I have been forced to experiment many times and I owe the progress I have made to my stubbornness ... I am back as a pupil'.

This kind of experiential learning by trial and error has enabled many teachers to become aware of their limits and address them using their skills. In their opinion, this challenge has necessarily led them to a more significant commitment than traditional training courses, which focus mainly on listening and/or on already prepared activity paths. However, some participants stressed the need for more time to experiment and more extrinsic feedback to guide and support their individual work.

In addition to learning by doing, a lot of importance was given to collaboration. This aspect was not only faced theoretically during the course but also applied in practice in the second part of the course so that participants could see its relevance, even in distance learning, and its usefulness for their learning path. Almost all of the teachers (91.9\%) said they had no difficulty collaborating remotely with colleagues, and $13.9 \%$ defined it as a strength of the course.

T4: 'The remote collaboration with colleagues was a strength. It has created a serene atmosphere of greater union and cohesion between us. We used the Gsuite Meet platform to work together'.

T5: 'This course stimulated us to experiment autonomously with the various coding/robotics activities, but also to design in a more profitable way with colleagues, making us even more collaborative despite the distance; this was the added value for me'. 
T6: 'The group work was carried out through the Gsuite Meet platform and was an important moment of confrontation and enrichment in the relationship through mutual help, support, encouragement and assistance'.

The comparison with colleagues was, therefore, considered something necessary and enriching for this training course. Nevertheless, some participants $(15.8 \%)$ expressed the need for face-to-face collaboration.

The last potential is closely linked to the previous results and highly relevant in terms of the success of the course. Many of the collected observations seem to prove a real increase in self-efficacy.

T7: '[...] We now have more familiarity and theoretical knowledge about these aspects of educational robotics and we can better promote learning processes. Thanks to this course, we have understood that we can learn through robotics, from robotics and with robotics; therefore, it is an excellent method to apply in the classroom involving more interdisciplinary aspects'.

T8: 'The more conscious and secure use of IT devices will make it easier for us to implement activities'.

T9: 'Trying and trying again and going ahead alone by trial and error has increased my motivation and allowed me to acquire greater confidence and awareness in progressing in learning new procedures'.

T10: 'I think that at the beginning of the next school year, it will be easier to implement coding/robotics and collaboration activities, as with the course I had the opportunity to experience them directly, acquiring more skills, knowledge about tools and strategies, appreciating their value. Having carried out these activities at a distance has stimulated in me the desire to put them into practice in presence with pupils and colleagues'.

The expansion of knowledge about content, methods and tools has led to an increase in self-confidence and motivation to practise what has been learned and designed. Most of the teachers (73.7\%) gave a positive response to the implementation of coding/robotics and collaboration activities at the beginning of the next school year. Participants appreciated the moments of reflection in school reality and the concrete design. Many of them recognize the greater confidence and familiarity acquired through tutorials, reflections on the returned tasks and experimentation. By acquiring more mastery over these tools, teachers feel able to help pupils experience them and promote learning processes the best way possible. Coding and robotics have been considered valuable tools to start again following the lock-down and involve pupils no longer used to listening. However, there is also a request for patterns to be followed based on previous experiences and the concern about implementing the designed paths in distance learning.

Among the added values of this distance learning course, participants have mainly emphasized the flexibility of time and space offered by the course organization compared to those in presence. The possibility for the teachers to refer to the material at any time and as many times they wanted has, in fact, allowed them to do so in a more profitable way, managing their time and not losing any important information.

Some teachers also appreciated the opportunity to attend the lessons from home, avoid distractions and confusion and carry out their tasks without stress. They, therefore, had more time to analyse, experiment and re-check the assigned activities.

Finally, participants were able to learn the use of a digital platform that was previously unknown. In particular, they rated how user-friendly classroom was, with an average score of 4.46 (on a 5-point Likert scale) and its usefulness as a working environment with an average score of 4.49 .

\section{Conclusions}

Considering the initial research questions, we believe that there are several reasons why this training course can be viewed as a third space between academic and school culture. The implementation of the course has led to the creation of a hybrid space between traditional in-presence training and entirely online courses, enriched by the possibility of participating, experimenting and comparing with colleagues. In this sense, it has been identified as a community space, a place where the formal and informal space of the learning environment intersects and creates a shift in the organization of learning and the construction of knowledge (Gutierrez et al., 1995).

The adopted working methods have also fostered a new approach to the course completion giving more flexibility in the use of time and space. Moreover, they allowed first-hand experimentation, often by trial and error, a collaborative approach among participants, and the wish to put into practice what had been learned and designed. This desire arises from greater confidence in own skills and expertise, primarily resulting from activities, reflections and feedback shared with colleagues and trainers. The opportunities for mutual exchange have been precious for the trainers to catch the needs, peculiarities and difficulties of the teaching staff of the various educational stages. This opportunity was, in turn, fundamental for the calibration of this training course and the improvement of future ones.

Moreover, teachers had the chance to view the material or participate meetings of any educational stages. This proved to be very important to improve the curriculum's verticality and promote an exchange within the same institution and thus within the same school culture. Teachers have also considered it an advantageous way to work and design, referring to their school reality to produce a learning design that could be applied during the following school year.

In conclusion, compared to the security of traditional training and the rigidity of online courses (mainly based on passive listening), this approach was appreciated because it led participants to: do it by themselves (constructivist approach); share among peers (peer-to-peer approach); face a challenging task (for both researchers and teachers); experience the difference between a push approach (rigid traditional didactics) and pull approach (possibility to choose 
the tasks independently to be committed to and the training path) and act in the boundary space between the everyday practice and the practice suggested by the university researchers.

\section{References}

Bhabha, H. (1994). The location of culture. London: Routledge.

Engeström, Y., Engeström, R., \& Kärkkäinen, M. (1995). Polycontextuality and boundary crossing in expert cognition: Learning and problem solving in complex work activities. Learning and Instruction, 5(4), $319-336$. https://doi.org/10.1016/0959-4752(95)00021-6

Engeström, Y. (2004). New forms of learning in co-configuration work. Journal of Workplace Learning, 16(1-2), 1121. https://doi.org/10.1108/13665620410521477

Flessner, R. (2014) Revisiting Reflection: Utilizing Third Spaces in Teacher Education. The Educational Forum, 78(3), 231-247, https://doi.org/10.1080/00131725.2014.912711

Gutierrez, K.D., Rhymes, B., \& Larson, J. (1995). Script, counterscript, and underlife in the classroom: James Brown versus Brown v. Board of Education. Harvard Educational, 65(3), $445-471$. https://doi.org/10.17763/haer.65.3.r16146n25h4mh384

Gutiérrez, K.D. (2008). Developing a Sociocritical literacy in the third space. Reading Research Quarterly, 43(2), 148164. https://doi.org/10.1598/RRQ.43.2.3

Hagel III, J., Brown, J.S., \& Davison, L. (2012). The power of pull: How small moves, smartly made, can set big things in motion. New York: Basic Books.

King, F. (2019). Professional learning: empowering teachers? Professional Development in Education, 45(2), $169-172$. https://doi.org/10.1080/19415257.2019.1580849

Martin, S.D., Snow, J.L., \& Franklin Torrez, C.A. (2011). Navigating the Terrain of Third Space: Tensions With/In Relationships in School-University Partnerships. Journal of Teacher Education, 62(3), $299-311$. https://doi.org/10.1177/0022487110396096

Murray, J., \& Male, T. (2005). Becoming a teacher educator: Evidence from the field. Teaching Teacher Education, 21(2), 125-142. http://dx.doi.org/10.1016/j.tate.2004.12.006

Potter, J., \& McDougall, J. (2017). Digital Media, Culture and Education. Theorising Third Space Literacies. London: Palgrave Macmillan.

Rivoltella, P.C. (2020). New Literacies. Essere a scuola, 1-2.

Swennen, A., Shagrir, L., \& Cooper, M. (2009). Becoming a teacher educator: Voices of beginning teacher educators. In A. Swennen, \& M. van der Klink (Eds.), Becoming a teacher educator (pp. 91-102). Dordrecht: Springer. https://doi.org/10.1007/978-1-4020-8874-2

Taylor, M., Klein, E.J., \& Abrams, L. (2014). Tensions of reimagining our roles as teacher educators in a third space: Revisiting a co/autoethnography through a faculty lens. Studying Teacher Education, 10(1), 3-19. https://doi.org/10.1080/17425964.2013.866549

Tardif, M. (2013). Où s' en va la professionnalisation de l'enseignement?. Tréma, (40), 42-59.

Timperley, H., Wilson, A., Barrar, H., \& Fung, I. (2007). Teacher professional learning and development: best evidence synthesis iteration [BES]. Wellington: Ministry of Education.

van Velzen, C., van der Klink, M., Swennen, A., \& Yaffe, E. (2010). The induction and needs of beginning teacher educators. Professional Development in Education, 36(1-2), 61-75. https://doi.org/10.1080/19415250903454817

Williams, J. (2014). Teacher educator professional learning in the third space: implications for identity and practice. Journal of Teacher Education, 65(4), 315-326. https://doi.org/10.1177/0022487114533128

Zeichner, K. (2010). Rethinking the Connections Between Campus Courses and Field Experiences in College- and University-Based Teacher Education. Journal of Teacher Education, 61(1-2), 89-99. https://doi.org/10.1177/0022487109347671

Wittorski, R. (2008). Professionnaliser la formation: enjeux, modalités, difficultés. Formation emploi. Revue française de sciences sociales, (101), 105-117. 